\title{
Methodological considerations for a model of endodontic treatment in Wistar rats
}

\author{
Sharon R. Oyhanart ${ }^{1}$, Mariela C. Canzobre ${ }^{1,2,3}$ \\ 1. Universidad de Buenos Aires, Facultad de Odontología, Cátedra de Histología y Embriología. Buenos Aires, Argentina. \\ 2. Universidad de Buenos Aires, Facultad de Medicina. Instituto de Biología Celular y Neurociencias "Prof. E. de Robertis" \\ Buenos Aires, Argentina. \\ 3. Consejo Nacional de Investigaciones Científicas y Técnicas. Buenos Aires, Argentina.
}

\begin{abstract}
The use of correctly designed animal models is a fundamental step prior to clinical trials in humans. Although rats are easy to house and handle, and have molars that resemble those of humans, very few researchers use them as a model for root canal treatment, probably due to their small size and the lack of relevant data necessary to reproduce the model. Our aims were to describe the anatomic and histologic characteristics of the mandibular first molar of the Wistar rat and present a standardised model for its experimental endodontic treatment. Twenty female rats were used. The characteristics of the mesial and distal roots were described histologically and the quality of the results achieved following the treatment protocol presented herein was assessed by means of digital radiographs, micro-
\end{abstract}

$C T$ and histological sections. The age of 55 days was found to be the most adequate for performing this technique, but we consider the interval of 50 to 60 days to be suitable. Both canals are oval, although in opposite planes, and the furcating-facing walls present the minimum dentine thickness. It was essential to become familiar with these aspects in order to decide upon the most appropriate instrumentation and obturation techniques that would enable replication of this model in basic science research.

Received: September 2020; Accepted: October 2020.

Keywords: endodontics - laboratory animal models - rats anatomy and histology - root canal.

\section{Consideraciones metodológicas para el modelo de tratamiento endodóntico en ratas Wistar}

\section{RESUMEN}

El uso de modelos animales correctamente diseñados es un paso fundamental previo al desarrollo de ensayos clínicos en humanos. A pesar de resultar fáciles de criar y manipular y de poseer molares que se asemejan a los humanos, muy pocos grupos utilizan a la rata como modelo experimental para el tratamiento endodóntico probablemente debido a su pequeño tamaño y a la escasa información disponible para poder aplicar los modelos existentes. Nuestros objetivos fueron describir las características anatómicas e histológicas del primer molar inferior de la rata Wistar y presentar un modelo estandarizado para el tratamiento endodóntico experimental de esta pieza. Se utilizaron 20 ratas hembra. Las características de las raices mesial y distal fueron descritas histológicamente y los resultados obtenidos fueron evaluados mediante radiografias digitales,

\section{INTRODUCTION}

Animal models are fundamental in dental research, especially in the field of Endodontics, as many aspects of periapical tissues and their response and
microCT y cortes histológicos. La edad de 55 días demostró ser la más adecuada para ejecutar la técnica, pero consideramos que el intervalo de 50 a 60 dias puede resultar apropiado. Se observó que ambos canales presentan una morfología oval, aunque en direcciones opuestas, y que las paredes furcales resultaron ser las que presentan el menor espesor de dentina. Familiarizarse con estos aspectos de la anatomía e histología del molar de la rata resultó fundamental para decidir sobre las técnicas de preparación y obturación más apropiadas que permitieran la replicación de este modelo en el campo de las ciencias básicas.

Palabras clave: endodoncia - modelo experimental - ratas anatomía e histología - conducto radicular.

healing impose an ethical barrier for their assessment in humans, and they are better explored in animal models that allow histological evaluation. These models include different species, from rodents ${ }^{1-4}$ to 
animals higher up in the phylogenetic scale such as $\operatorname{dogs}^{5-7}$ and primates ${ }^{8}$.

Wistar rats were selected in the present study because they can be easily housed and handled, and enable histological sections to be obtained relatively fast, at a lower acquisition and maintenance cost, with fewer breeding, management and ethical concerns. Furthermore, the reaction of their pulpal ${ }^{3}$ and periapical tissues ${ }^{9}$ is similar to that of humans, which makes them a suitable option for experimental models in Endodontics.

Albino rats lack primary dentition -they are monophyodont- and present four permanentlygrowing incisors with a wide-open apex separated from the three molars in each quadrant by a large diastema. Interestingly, rat molars present developmental, anatomical, histological and physiological features similar to those of human teeth ${ }^{10}$. The mandibular first molar of the rat is the largest and has four roots-one mesial, one distal and two smaller central ones on the buccal and lingual side, respectively ${ }^{10}$. In 1967, the research group led by Erausquin at the School of Dentistry of the University of Buenos Aires described a protocol for performing the root canal treatment of the mesial root of this molar, in accordance with the existing endodontic procedures, in order to study the reaction of the periapical tissues in response to different root canal sealers ${ }^{4}$. However, to date, few research groups have used the rodent model of experimental endodontics in vivo in their lines of research, which can range from periapical repair ${ }^{1,2}$ to post-endodontic pain ${ }^{11}$. In fact, when it comes to evaluating endodontic sealers, subcutaneous implantation models are preferred ${ }^{12,13}$. It is likely that the scant research using this model is largely due to the difficulty of the technique and the lack of studies describing a standardised protocol according to age and size of the animals, as well as to the lack of information on the morphology of the root canal system of the rat molar. Such information is vital to predictable endodontic treatment ${ }^{14}$, since what is not known cannot be adequately treated.

Given the need to present relevant data regarding the reproducibility of the model, the aim of the present study was to describe the anatomic and histologic characteristics of the mandibular first molar of the Wistar rat and to develop a standardised model for experimental root canal treatment of this tooth.

\section{MATERIALS AND METHODS}

The experimental protocol and use of animals in the present study was authorised by the Institutional Committee for the Care and use of Laboratory Animals of the School of Dentistry, University of Buenos Aires (CD No. 012/2016 CICUAL - ODON/ FOUBA) and all procedures were performed in accordance with the $20118^{\text {th }}$ edition of the National Research Council Guide for the Care and Use of Laboratory Animals. Animals were housed in cages in groups of two or three per cage at the animal facility in the Department of Histology and Embryology of the School of Dentistry of University of Buenos Aires under 12:12 h light/dark cycles, and allowed ad libitum access to food (standard chow, Cooperación, Buenos Aires, Argentina) and water.

\section{Characterisation of the mandibular first molar in control animals}

For the first stage of this study, 15 healthy female Wistar rats were divided into three groups $(n=5)$ according to age $-30,55$ and 75 days - for histologic analysis of the length of the mesial and distal roots of the mandibular first molars. Thereafter, the characteristics of the root canals and walls were further assessed in animals from the age group in which root length was found to be optimal for endodontic procedures, using mesio-distally and bucco-lingually oriented sections $(n=5$ right and $\mathrm{n}=5$ left molars).

\section{Root canal treatment procedure in experimental animals}

For the second stage of this study, aimed at standardising the endodontic procedure, 50- to 60-day-old healthy female Wistar rats $(n=5)$ weighing about $180 \mathrm{~g}$ were used. Animals were anaesthetised with a combination of $50 \mathrm{mg} / \mathrm{kg}$ of ketamine (Ketamid; Holliday-Scott S.A., Beccar, Buenos Aires, Argentina) and $10 \mathrm{mg} / \mathrm{kg}$ of xylazine (Kensol; König S.A., Avellaneda, Buenos Aires, Argentina) administered i.p. in order to attain deep levels of anaesthesia. Procedures were carried out using a stretcher that incorporated original modifications to the one described by Erausquin in 1967': once anaesthetised, the animal is laid in dorsal position and its head immobilised by the upper incisors, which are placed through a metal wire attached to the headrest. Mouth opening, tongue separation and mandibular first molar isolation 
are achieved by an ad hoc aluminium clamp with projections that grip the first molar and an orifice for securing the lower incisors. This makes the mandibular first molar readily accessible (Fig. 1) and enables its isolation, enhanced by the placement of light-cured resin barrier. All procedures can thus be performed without difficulty. Prior to endodontic access, the surface of the isolated molar was cleaned using $0.5 \%$ sodium hypochlorite. The mesial pulp horn was then exposed by drilling a small hole through the roof of the pulp chamber using a size $1 / 4$ round dental bur mounted on an electric enginedriven micromotor and placed on the mesial pit with a disto-mesial inclination. Using the same bur, the distal pulp horn was immediately exposed and a size $1 / 2$ round dental bur was used to refine the access until all four root canal orifices were visible. While performing these procedures, it is important to bear in mind that the cusp tips are separated from the pulp chamber floor by only $1.5-2 \mathrm{~mm}$, so care is required to avoid perforation (Fig. 2).

Initial catheterisation was performed using a \#08 K-file (Dentsply Sirona, Ballaigues, Switzerland) and a working length of $4 \mathrm{~mm}$ (Fig. 2), and confirmed using an electronic apex locator (Root ZX mini; J Morita corp., Tokyo, Japan). Root canal enlargement was performed using K-files \#10 to \#25 with in and out and clockwise and counter-clockwise rotation motions. At each change of instrument, canals were irrigated with $0.3 \mathrm{ml}$ of freshly-prepared $2.5 \%$ sodium hypochlorite delivered by means of

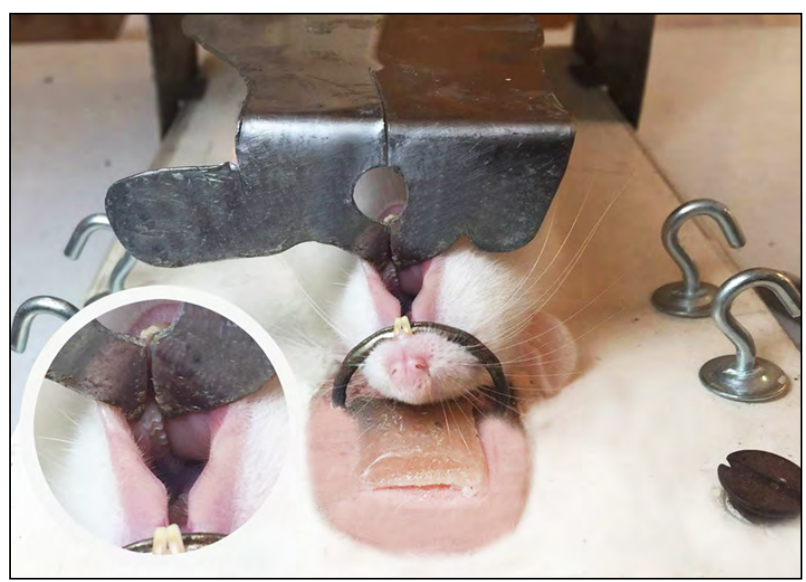

Fig. 1: A metal wire holds the upper incisors, immobilising the head, while a specially designed clamp integrated into the stretcher fixes the position of the lower jaw, keeping the mouth open and displacing the tongue and cheek, thus making the intact mandibular first molar clearly visible and accessible for access and further preparation and obturation. a carpule dental syringe and an extra-short 30G needle (Misawa Medical Industry, Kasama City, Ibaraki Prefecture, Japan) while aspirating it with a micro-cannula (Roeko SurgiTip-Endo; Coltène/ Whaledent, Altstätten, Switzerland). In central canals -buccal and lingual- only \#08 and \#10 K-files were used in order to achieve pulp removal without further enlargement, given the thinness of their walls.

Canals were then dried using sterile paper points \#25 and filled with a \#25 gutta-percha master cone, accessory FF cones (Meta Biomed; Cheongju, North Chungcheong, South Korea)-both previously decontaminated in $2.5 \%$ sodium hypochlorite- and a ZOE-based sealer (Grossman's Root Canal Sealer; Farmadental, Buenos Aires, Argentina) using cold lateral condensation technique and paying special attention to the distinctive morphology of each canal. After sectioning the filling material to the cervical level with an adapted heated \#40 digital plugger (VDW, München, Germany) and vertically compacting it, the pulp chamber was filled with light-cured glass-ionomer cement (SDI Riva, Victoria, Australia).

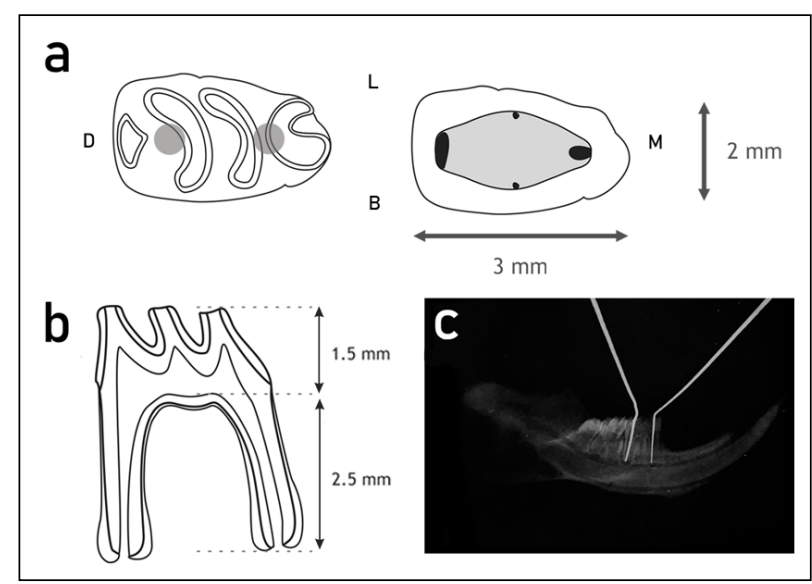

Fig. 2: a) Diagram of the occlusal and pulp chamber topography of the mandibular first molar and the size of the crown. Adequate refinement of the endodontic access enables visualisation of the mesial, distal, and the smaller buccal and lingual root canal orifices. M: mesial, L: lingual. Grey dots mark the starting location for penetration of the pulp chamber roof. b) Diagram of the internal anatomy of the mandibular first molar. The distance between the molar cusp tips and the pulp chamber floor is $1.5 \mathrm{~mm}$ and from this point to the root apex, $2.5 \mathrm{~mm}$. Note the scarce dentine thickness separating the pulp chamber from the furcal area, resulting in high risk of perforation during the access phase. Buccal and lingual roots are not depicted. c) Radiograph of a 55-day-old rat hemimandible (ex vivo) showing files placed in the mesial and distal canals at a working length of $4 \mathrm{~mm}$. 
After recovery from anaesthesia, animals were monitored for signs of discomfort or pain, including alteration of feeding and hydration patterns and behaviour, to detect any unexpected post-treatment reaction. If any of the animals showed signs of severe pain according to the score suggested by Wolfensohn and Lloyd ${ }^{15}$, or any signs of infection, they were to be removed from the experimental group and administered antibiotic and/or analgesic medication. However, this was not necessary, as all operated animals returned to normal behaviour, including feeding and social interaction, after the first day post-treatment. After two weeks, animals were euthanised by i.p. injection of a lethal dose of pentobarbital sodium (Euthanyle; Brouwer S.A., Buenos Aires, Argentina) at approximately the same time of the day in order to minimise the effect of changes owed to circadian rhythm. Right and left hemimandibles were dissected and fixed in buffered formalin ( $\mathrm{pH} 7.3-7.5)$ for $48 \mathrm{~h}$.

\section{Radiographic analysis}

Radiographic analysis of the endodontically treated molars was performed by taking periapical radiographs of hemimandibles using a digital sensor (MyRay; Imola, Bologna, Italy) and a dental X-ray unit operated at $70 \mathrm{kV}$ and $8 \mathrm{~mA}$, with a $15 \mathrm{~cm}$ sourceto-object distance and 0.15 -second exposure time.

\section{Micro-tomographic analysis}

Micro x-ray computed tomography of endodontically treated molars was carried out using a custom attachment and a micro-CT system (SkyScan 1272; Bruker, Kontich, Belgium). Scans were obtained using a tube voltage of $90 \mathrm{kV}$ and current of 110 $\mathrm{mA}$ through 180 rotation around the vertical axis with a rotation step of 0.2 . Image pixel resolution was $15 \mu \mathrm{m}$ and a $0.5 \mathrm{~mm}$ aluminium filter was used to reduce beam hardening. Projection images were reconstructed using NRecon v.1.7.3.1 software (Bruker, Kontich, Belgium) and Data Viewer software (Bruker, Kontich, Belgium) was used to obtain representative images.

\section{Histologic and histomorphometric analysis}

Following decalcification in EDTA $10 \% \mathrm{pH} 7$ for 5 weeks, hemimandibles were dehydrated and embedded in paraffin, and serial sections of the mandibular first molars of approximately $7 \mu \mathrm{m}$ were obtained. Mesio-distally (MD) and bucco-lingually
(BL) oriented sections were obtained from control animals to study the characteristics of this molar while mesio-distally (MD) oriented sections were obtained from experimental animals to evaluate the quality of the treatment; both were stained with haematoxylin-eosin (HE). Only sections in which continuity between coronal and radicular pulp and between the latter and the apical periodontal ligament was evident were selected, in order to ensure adequate orientation of the axis of each root. Digitalised microphotographs were then taken with a light microscope (Nikon Eclipse Ni, Nikon Instruments Inc, Melville, NY, USA) and analysed using ImagePro Plus 4.5.0.29 software to determine:

- The length of the mesial and distal roots (MR, DR) in MD sections of the initial three animal groups (i.e. 30, 55 and 75 days old). In order to do this, one tangent line was drawn to the pulp chamber floor and another one to the root apex, and the distance between the two measured perpendicularly to them and running through the centre of the corresponding root canal.

- The width of the root canal and the thickness of the furcal (F), external (E), buccal (B) and lingual (L) walls in the cervical (C), middle (M) and apical (A) thirds in MD and BL sections of the 55-day-old animals. For each wall, total and dentine thickness were measured along nine straight parallel equidistant lines each. Three determinations per third were averaged to obtain a single value for each parameter and third. The thickness corresponding to cementum was calculated as the difference between the aforementioned measurements.

\section{Statistical analysis}

InfoStat v2019 was employed. Normality of data distribution was verified through Shapiro-Wilk test. All the results were expressed as mean and standard deviation (SD), and analysed statistically using ANOVA followed by Tukey's post-hoc test, setting the significance level at $5 \%$.

\section{RESULTS}

\section{Histomorphometric description of the mandibular first molar}

The histologic characteristics of the roots of the mandibular first molar of 30, 55 and 75 day old rats were analysed. In 30 day old animals, root 
development was still incomplete, with thin root canal walls, a wide root canal, a wide-open apex and the presence of Hertwig's Epithelial Root Sheath (HERS) (Fig. 3a). Animals aged 55 days had a completely developed apex with no evidence of HERS (confirming that the radicular dentine had reached its maximum length), cementum lining the external surface and increased root canal wall thickness (Fig. 3b). In older animals (75 days old) further cellular cementum deposition occurred at the apex, sometimes invading the apical third of the canal, thus increasing radicular length and altering apical morphology (Fig. 3c). The length of the mesial and distal roots did not differ significantly. However, mean root length increased progressively and significantly from 30 days $(1.9 \pm 0.24 \mathrm{~mm})$, to 55 days $(2.5 \pm 0.18 \mathrm{~mm})$ and up to 75 days of age $(3.1 \pm 0.11 \mathrm{~mm})$ (Fig. 4).

These histological observations led us to rule out the 30- and 75-day-old groups from further endodontic protocol experiments and to select the 55-day-old group for the rest of the radicular analysis and experimental root canal treatment. In these animals, in addition to root length, root canal width and wall thickness of both mesial and distal root canals were measured in both orientations (MD and BL) and all three radicular thirds (cervical, middle and apical).
The mean width $(\mu \mathrm{m})$ of the mesial root canal was significantly greater in the MD direction (MD: $293 \pm 120$ vs BL: $165 \pm 54, p<0.0001)$, while the distal root canal was found to be wider in the BL direction (MD: $192 \pm 69$ vs BL: $398 \pm 147, p<0.0001$ ) (Fig. 5). The analysis of all four root canal walls (furcal, external, buccal and lingual) showed that the relationship between dentine and cementum is inversely proportional in each of the three thirds as the greatest thickness corresponds to dentine in the cervical third and cementum in the apical third. Considering these parameters, we can state that the total wall thickness $(\mu \mathrm{m})$ remains constant (without significant differences between thirds) showing a progressive decrease in dentine and increase in cementum thickness from the cervical to the apical third ( $p<0.0001$ between thirds of each root canal wall) (Fig. 5 and Table 1).

Since preserving dentine is an important aspect of endodontic shaping procedures, dentine thickness $(\mu \mathrm{m})$ was analysed within each root (MR and DR) in each of the three thirds ( $\mathrm{C}, \mathrm{M}$ and $\mathrm{A})$ and considering all four walls (F, E, B and L). The furcal wall was found to be the thinnest in both roots, and this was significantly more noticeable in the cervical third of the mesial root (MRC: F: $154 \pm 27, \mathrm{E}: 256 \pm 33$, L: $233 \pm 32$, B: $237 \pm 19, p<0.0001)$ and the middle third

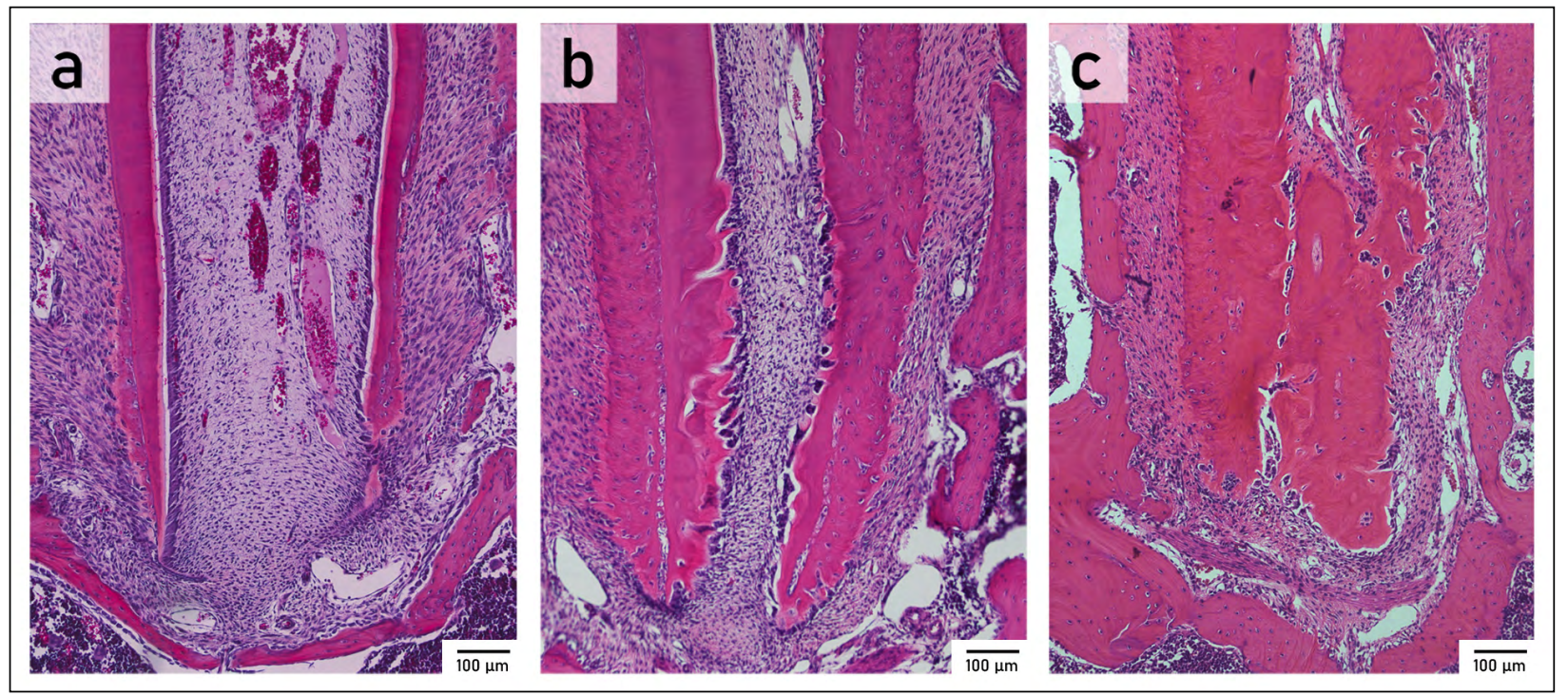

Fig. 3: Microphotographs of HE stained histological sections of the distal root of the mandibular first molar depicting different stages of root development. In 30-day-old animals a) root development is still incomplete and Hertwig's Epithelial Root Sheath (HERS) can still be observed. By 55 days of age b), radicular dentine has been completely laid down, with cementum laid parallel and externally to it and no evidence of HERS. In 75-day-old animals c) greater amounts of cellular cementum can be seen at the root apex, increasing radicular length and often invading the apical third of the root canal, thereby altering canal morphology. Bars represent $100 \mu \mathrm{m}$. 


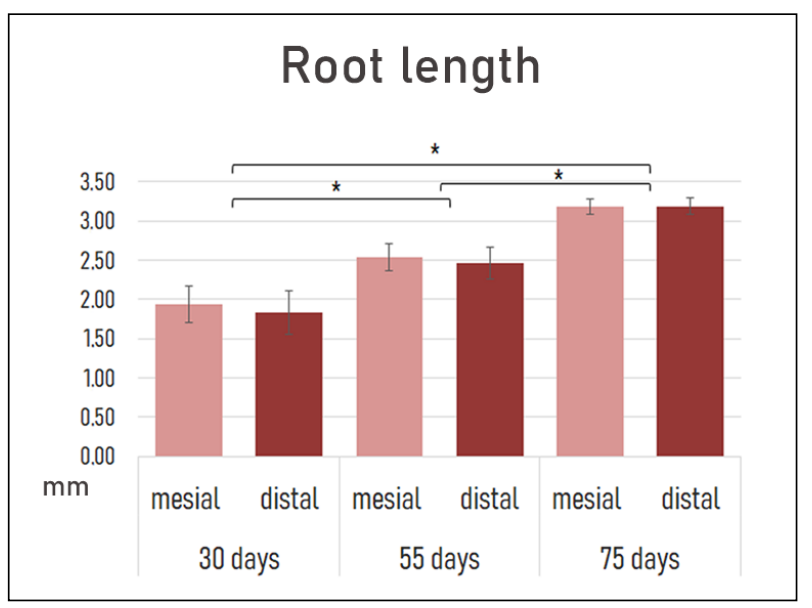

Fig. 4: The graph shows the mean length and SD (in $\mathrm{mm}$ ) of the mesial and distal roots of the mandibular first molar. No differences were found between roots within each age group but root length was found to increase significantly with age $(p<0.0001)$.

of the distal root: F: $98 \pm 10$, E: $176 \pm 20$, L: $237 \pm 43$, B: $184 \pm 42, p<0.0001)$ (Fig. 5 and Table 1).

\section{Post-endodontic observations}

The average time needed to perform each root canal treatment was 40 minutes, from the time of drilling for endodontic access to placing the coronal seal. When the animals were euthanised ( 2 weeks posttreatment), all coronal seals were intact and in place. Mesial and distal root canal fillings showed satisfactory radiographic or micro-tomographic three-dimensionality and adequate length, and there was no evidence of surrounding alveolar bone loss (Fig. 6). Histological observations were consistent with the aforementioned. Furthermore, no pulpal remnants were found in treated animals and the apical limit was confirmed to be correct (Fig. 7), demonstrating satisfactory achievement of the physical and chemical goals of chemomechanical preparation. The presence of remaining dentine surrounding the filling material proved that the calibre of the preparation was in accordance with the internal anatomy.

A moderate amount of lymphocytic infiltrate was observed in the periapical tissues, as well as the presence of small fragments of eosinophilic material with a tubular pattern resembling dentine, possibly consisting of debris or, in absence of this pattern, root canal sealer extruded during the shaping and obturation phases, respectively (Fig. 7). No areas of necrosis were observed within the adjacent periodontal ligament or cellular cementum.

\section{DISCUSSION}

Correctly designed animal models using rodents have been extensively used in dental research ${ }^{1-4,9,16,17}$ because these animals can be easily housed and handled and enable histological sections to be

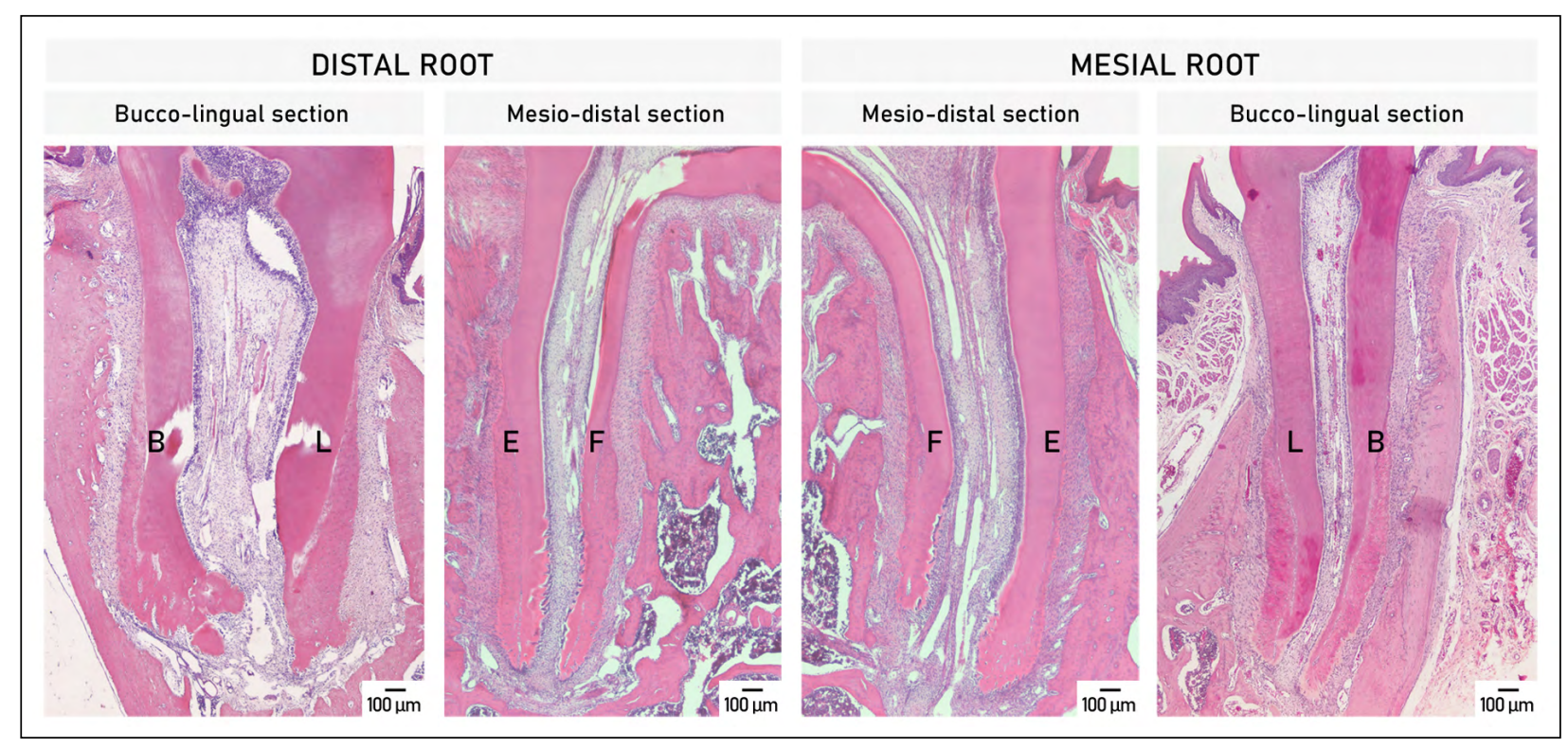

Fig. 5: Microphotographs of HE stained histological sections of the mesial and distal roots of the mandibular first molar. Buccolingual sections of both roots show an even thickness of buccal and lingual walls while mesio-distal sections reveal that furcationfacing walls are notably thinner. B: buccal, L: lingual, E: external, F: furcal. Original magnification $40 X$. Bars represent $100 \mu$ m. 
Table 1. Root canal wall thickness

Third Mesial root (55 days). Mean thickness ( $\mu \mathrm{m})$

\begin{tabular}{|c|c|c|c|c|c|}
\hline \multirow{4}{*}{$\frac{\bar{d}}{\bar{d}}$} & & Buccal & Lingual & External & Furcal \\
\hline & $\mathbf{T}$ & $242 \pm 19^{\mathrm{Aa}}$ & $238 \pm 32^{\mathrm{ABa}}$ & $259 \pm 33^{\text {Аa }}$ & $171 \pm 25^{\mathrm{Ba}}$ \\
\hline & D & $237 \pm 19^{\text {Аа }}$ & $233 \pm 31^{\mathrm{Aa}}$ & $256 \pm 32^{\text {Aa }}$ & $154 \pm 27^{\mathrm{Ba}}$ \\
\hline & C & $4 \pm 1^{\mathrm{Aa}}$ & $5 \pm 2^{\mathrm{Aa}}$ & $3 \pm 1^{\mathrm{Aa}}$ & $17 \pm 8^{\mathrm{Aa}}$ \\
\hline \multirow{3}{*}{$\frac{0}{\overline{0}}$} & $\mathbf{T}$ & $269 \pm 54^{\mathrm{Aa}}$ & $269 \pm 54^{\mathrm{Aa}}$ & $269 \pm 54^{\mathrm{Aa}}$ & $212 \pm 17^{A}$ \\
\hline & D & $169 \pm 10^{\mathrm{ABb}}$ & $190 \pm 26^{\mathrm{Aa}}$ & $209 \pm 16^{A b}$ & $144 \pm 19^{B}$ \\
\hline & C & $58 \pm 35^{\mathrm{Ab}}$ & $54 \pm 20^{\mathrm{Aa}}$ & $60 \pm 41^{\mathrm{Ab}}$ & $69 \pm 13^{A b}$ \\
\hline \multirow{3}{*}{ হ্তু } & $\mathbf{T}$ & $187 \pm 20^{\mathrm{Aa}}$ & $220 \pm 33^{\mathrm{Aa}}$ & $227 \pm 24^{\mathrm{Aa}}$ & $225 \pm 36^{\mathrm{Aa}}$ \\
\hline & D & $52 \pm 9^{\mathrm{Bc}}$ & $100 \pm 22^{\mathrm{Ab}}$ & $114 \pm 10^{\mathrm{AC}}$ & $73 \pm 10^{\mathrm{ABC}}$ \\
\hline & C & $135 \pm 14^{\mathrm{AC}}$ & $120 \pm 26^{\mathrm{Ab}}$ & $113 \pm 19^{A C}$ & $152 \pm 42^{A}$ \\
\hline
\end{tabular}

\begin{tabular}{c|c|c|c|}
\multicolumn{4}{c}{ Distal root (55 days). Mean thickness $(\boldsymbol{\mu m})$} \\
\hline Buccal & Lingual & External & Furcal \\
\hline $209 \pm 48^{\mathrm{Aba}}$ & $311 \pm 50^{\mathrm{Ba}}$ & $250 \pm 23^{\mathrm{Aba}}$ & $162 \pm 29^{\mathrm{Aa}}$ \\
\hline $198 \pm 48^{\mathrm{Aba}}$ & $300 \pm 50^{\mathrm{Ca}}$ & $245 \pm 21^{\mathrm{BCa}}$ & $155 \pm 31^{\mathrm{Aa}}$ \\
\hline $10 \pm 6^{\mathrm{Aa}}$ & $11 \pm 3^{\mathrm{Aa}}$ & $5 \pm 3^{\mathrm{Aa}}$ & $7 \pm 2^{\mathrm{Aa}}$ \\
\hline $253 \pm 40^{\mathrm{Aab}}$ & $311 \pm 56^{\mathrm{Aa}}$ & $236 \pm 29^{\mathrm{Aa}}$ & $125 \pm 9^{\mathrm{Ba}}$ \\
\hline $194 \pm 42^{\mathrm{Aa}}$ & $237 \pm 43^{\mathrm{Aa}}$ & $176 \pm 20^{\mathrm{Aa}}$ & $98 \pm 10^{\mathrm{Bab}}$ \\
\hline $69 \pm 24^{\mathrm{Aa}}$ & $75 \pm 23^{\mathrm{Aa}}$ & $60 \pm 25^{\mathrm{Aab}}$ & $27 \pm 14^{\mathrm{Aab}}$ \\
\hline $312 \pm 91^{\mathrm{Ab}}$ & $287 \pm 73^{\mathrm{Aa}}$ & $236 \pm 28^{\mathrm{ABa}}$ & $151 \pm 21^{\mathrm{Ba}}$ \\
\hline $100 \pm 38^{\mathrm{Ab}}$ & $89 \pm 23^{\mathrm{Ab}}$ & $104 \pm 8^{\mathrm{Ab}}$ & $48 \pm 6^{\mathrm{Ab}}$ \\
\hline $212 \pm 90^{\mathrm{Ab}}$ & $198 \pm 72^{\mathrm{Ab}}$ & $131 \pm 25^{\mathrm{Bb}}$ & $103 \pm 19^{\mathrm{ABb}}$ \\
\hline
\end{tabular}

The table shows mean and SD (in $\mu \mathrm{m}$ ) of the total, dentine and cementum thickness of the root canal walls of the mesial and distal roots of the mandibular first molar in the bucco-lingual (buccal and lingual walls) and mesio-distal (external and furcal walls) direction. T: total, D: dentine, C: cementum. For comparisons within each root, different lowercase letters indicate statistically significant differences between rows and different uppercase letters indicate differences between columns $(p<0.0001)$.

obtained relatively fast. In the field of Endodontics, larger animals such as dogs, whose teeth have a single canal and are more comparable in size to human teeth, have been preferred for studying root canal treatment procedures ${ }^{5-7}$. However, in addition to dogs being more expensive and often drawing opposition from public opinion ${ }^{18}$, it has been reported that their apical anatomy is complex and invariably presents an apical delta ${ }^{19,20}$, making them a less than ideal model for understanding the repercussions of root canal chemomechanical debridement and obturation on periapical tissues. Although scarce, some studies using the rat as a model for endodontic treatment are available in literature, the vast majority using the mandibular first molar: some have focused on treating either the mesial ${ }^{1,4}$ or distal ${ }^{21,22}$ root and even fewer have addressed both ${ }^{2,23}$. Sadly, the careful dissection of some of the endodontic treatments reported reveals suboptimal results regarding working length or excessive tapers which turn out to be inadequate for the root canal anatomy present in the rat. These problems are probably owed to the lack of studies describing a standardised protocol for root canal treatment in accordance with animal age, size and root canal morphology, as well as the adequate age for treatment. Moreover, to our knowledge, there is no study addressing the anatomic and histologic characteristics of the mandibular first molar of the Wistar rat.

According to early published data, in albino rats, molar crown formation is completed between postnatal days 11-21, and root development in first, second and third mandibular molar is completed by days 25,28 and 40 , respectively ${ }^{10}$. Nevertheless, the data presented in our study revealed that by day 25 , root development of the mandibular first molar is not yet complete and Hertwig's Epithelial Root Sheath (HERS) can still be observed. In our study, root development of the mandibular first molar was found to be complete at around day 55, which is in agreement with recent data ${ }^{2}$. From this age onwards, root length increases as a result of the continuous deposition of cellular cementum at the root apex. Interestingly, in adult rats, up to one third of the total root length can be composed of cementum alone. This mechanism, termed hypercementosis, is considered to be physiological, continuous ${ }^{24}$ and necessary to compensate for the attrition resulting from mastication and diet characteristics ${ }^{10}$, and potentially complicates the achievement of patency and satisfactory endodontic debridement and obturation. Taking all this into account, we decided to use Wistar rats aged 55 days which, according to histological observations, have a completely developed root (no HERS is observed) and cementum -including the cellular variety- lining the external surface of radicular dentine, sometimes extending slightly apically to it, and maintaining a relatively stable root length of $2.5 \mathrm{~mm}$ and a radicular canal that is accessible for instrumentation and the establishment of an apical stop.

Our findings regarding the distinctive anatomy of the mesial and distal canals revealed that both are oval, as within each sample the diameter in 


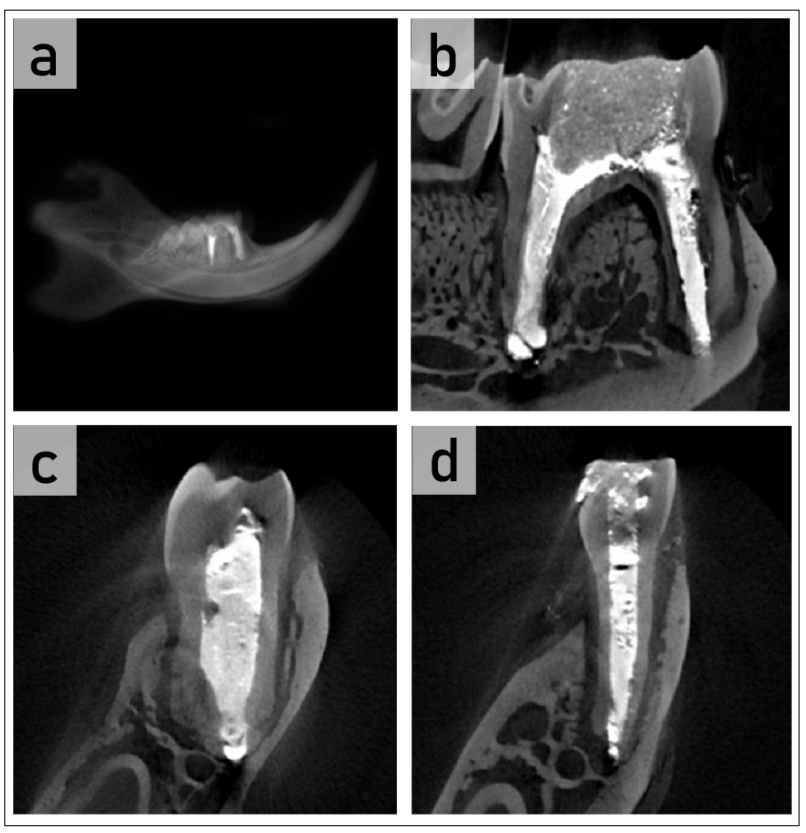

Fig. 6: Periapical radiograph of an endodontically treated a) molar depicts achievement of adequate working length and proper filling of both distal and medial root canals. This was confirmed by micro-tomographic slices that also enabled more detailed assessment of the condition of the surrounding bone. Sagittal slices b) confirmed that no stripping of the canal walls had occurred, which is consistent with an intact interradicular bone, while coronal slices of the distal c) and mesial d) roots showed correct adaptation of the obturation mass to the root canal walls and only small pores within it, even in the distal root c) which is fairly wide in the bucco-lingual plane. In some cases, a minor extrusion of sealer was seen through the foramen of both distal and mesial roots, but it seems not to have caused loss of apical bone.

one of the directions -either $\mathrm{MD}$ or $\mathrm{BL}$ - was two times greater than the diameter in the other direction $^{25}$. Furthermore, while the mesial canal was found to be wider in the mesio-distal plane, the opposite occurred with the distal canal. These characteristics should be taken into account when pondering the question of which type of preparation and obturation techniques to use. In terms of preparation, attention should be paid to cleaning and shaping the canal entirely in order to eliminate inflamed or necrotic pulp. Most rotary instruments produce a round preparation ${ }^{26,27}$, leaving unprepared recesses in oval-shaped canals $^{28}$. Even if this problem can be partially surmounted by the use of laterally directed brushing working strokes ${ }^{29}$, unfortunately this would not be feasible in the rat, given that the restricted angle for instrumentation and the short length of the roots limit the amplitude and control of movements. We therefore consider manual circumferential instrumentation to be more appropriate, as previously suggested for this type of anatomy in human teeth ${ }^{25}$.

In this regard, it is important to consider dentine thickness in each radicular third in order to preserve as much as microbiologically admissible, since excessive loss of dentine may contribute to increased susceptibility to fracture ${ }^{30}$. Even though micro-CT technology could prove to be a powerful non-destructive method for understanding the anatomy of the rat molar, segmentation of dentine and cementum based on pixel grey level values would be very difficult -if not practically impossible when considering acellular cementumand require very high resolutions, resulting in time-consuming scanning protocols (estimated resolution of $2 \mu \mathrm{m}$ or less, and $>10 \mathrm{~h}$ ). These difficulties are caused by the small size of the sample and the fact that dentine and cementum have similar mineral densities ${ }^{31}$. We therefore decided to use HE stained histological sections, which enabled us to identify and measure the thickness of each tissue ${ }^{32}$. We thus found furcation-facing walls to be thinner than their external counterparts, especially in the coronal third. This is analogous to what is observed in human molars, in which the limited amount of dentine associated with the concavity and root curvature makes them danger zones $^{33}$ where overzealous filing must be avoided in order to prevent strip perforations. An analysis of the diameters of different NiTi instruments with equal tip size (i.e. $0.25 \mathrm{~mm}$ ) over the first $3 \mathrm{~mm}$ of their active portion-including one used in a recent study proposing a model for root canal treatment in the $\mathrm{rat}^{2}$ - based on the premise that they produce centred preparations ${ }^{34}$ reveals that all of them would cause excessive thinning of dentine. In the direction in which each canal attains its minimum diameter -BL and MD for the mesial and distal canals respectively- this could take up from $33 \%$ to $97 \%$ of the dentine wall in the cervical and middle thirds of the root, depending on the system, while the use of $\mathrm{K}$ files of equal diameter would cause a decrease in thickness of no more than 39\%. This shows that more conservative tapers (i.e. $2 \%$ ) should be preferred to larger tapers (i.e. $4 \%, 6 \%$, $7 \%, 8 \%)$. As for the obturation phase, a single cone technique would not be likely to satisfactorily fill the entire canal space, which is why we consider 

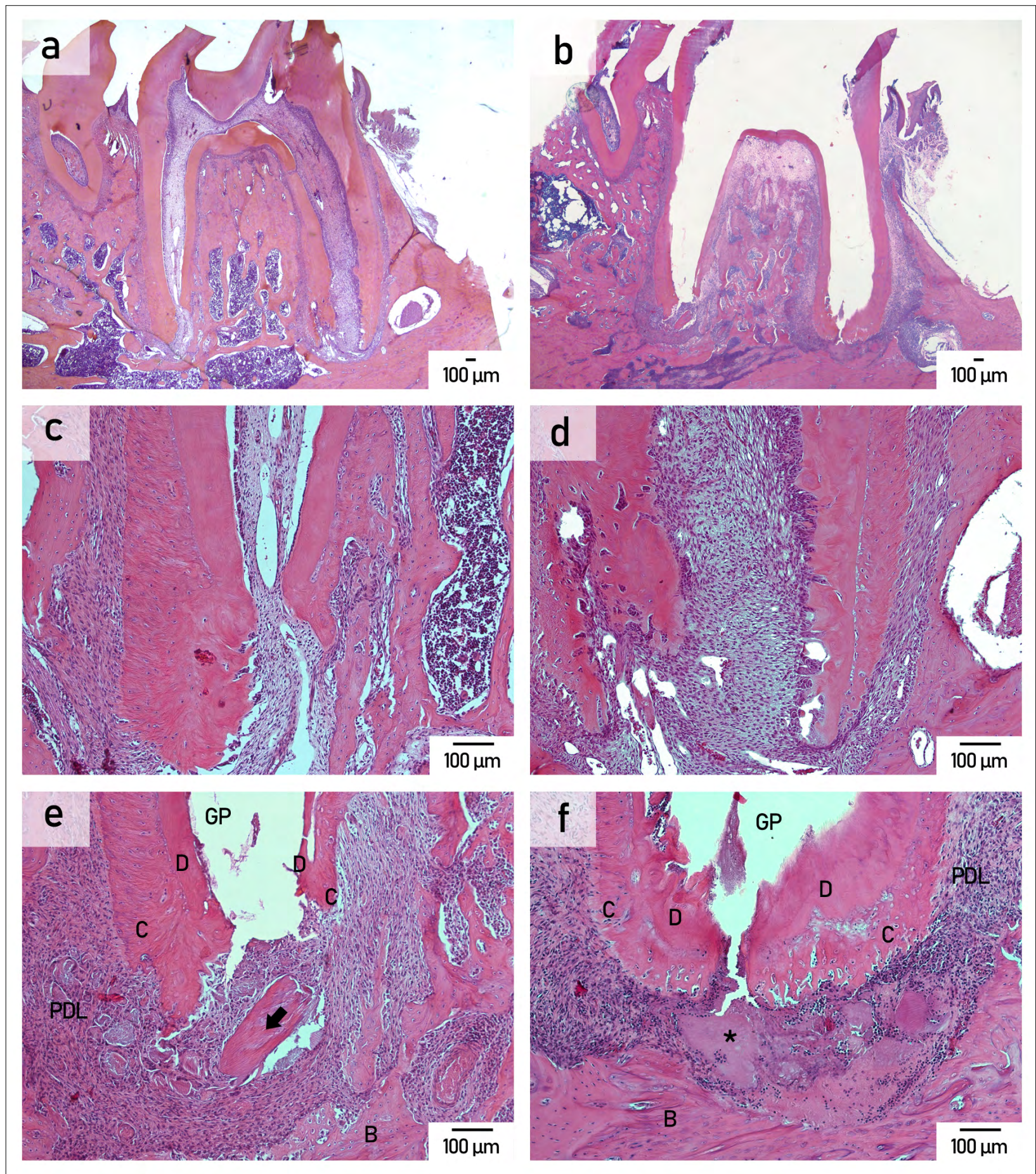

Fig. 7: Microphotographs of HE stained histological sections of a control $a, c, d)$ and an endodontically treated molar $b$, $e$, $f$ ). Comparison shows that the preparation technique achieved satisfactory elimination of dental pulp tissue at an adequate working length and an apical size in accordance with the anatomy of each root. Original magnification $20 X(a-b)$ and $100 X(c-f)$. GP: guttapercha, PDL: periodontal ligament, D: dentine, $C$ : cellular cementum, B: bone, $\rightarrow$ : dentine debris, *: extruded root canal sealer. Bars represent $100 \mu \mathrm{m}$. 
cold lateral condensation with accessory guttapercha points to be a better choice.

Another important aspect is final restoration of the access cavity, which has been shown to have impact on the rate of success of endodontic therapy ${ }^{35}$ and is important in preserving the treatment throughout experiment. Materials such as amalgam, as proposed by other groups ${ }^{22}$, tend to result in lack of retentiveness due to the shallowness of the access cavity (1.5 $\mathrm{mm}$ in depth) or cracks/fracture of the walls upon compaction. The use of composites, on the other hand, demands a strict adhesive technique and, once cured, can result in premature contacts that would lead to a state of inflammation of the periodontal ligament, in addition to muscle fatigue and/or temporomandibular joint disorders ${ }^{36}$. Furthermore, their high elastic modulus could complicate the obtention of histological sections using a microtome once the hemimandible has been decalcified. We therefore suggest the use of type II restorative glass-ionomer cement, given its compressive and tensile strength, as well as its excellent adhesion to dentine and enamel and hardness that permits surface wear when in occlusion with the antagonist tooth ${ }^{37}$. Other groups have also used this material ${ }^{1,21,23}$. In our experience, a thorough removal of excess gutta-percha from the pulp chamber is key to guaranteeing sufficient contact of the material with the walls and to ensure greater longevity of the restorations.

In view of achieving operator training and carrying out a successful treatment, we have considered the methodological steps followed and prepared the following protocol and recommendations for experimental root canal treatment in Wistar rats:

- Select appropriately aged animals in order to avoid intraoperative complications. We found 55-day-old rats to be optimal models, but consider the interval of 50 to 60 days of age to be adequate.

- Attain deep levels of general anaesthesia for up to $40-60$ minutes.

- Use a stretcher that provides proper positioning of the animal's head and enough mouth opening in order to ensure clear visualization view of the molar and operator's access to perform shaping, cleaning and filling procedures.

- Use a specially designed clamp and an aspiration micro-cannula to enable soft-tissue separation and provide a thoroughly dry field while maintaining oropharynx permeability and avoiding ingestion and/or obstruction of the respiratory airway.

- Position the dental bur on the mesial pit with a disto-mesial inclination so as to enter the mesial pulp horn and avoid perforation of the pulp chamber floor.

- Perform catheterisation of the canals using \#08 $\mathrm{K}$-files and confirm working length (estimated in $4 \mathrm{~mm}$ ) using an electronic apex locator.

- Shape and enlarge mesial and distal canals using manual circumferential instrumentation because of their oval shape and using the minimum taper available (i.e. $2 \%$ ) because of the thinness of their walls.

- Fill canals using a cold lateral condensation technique instead of a single cone technique, given the oval shape of the canals.

- Remove excess gutta-percha from the pulp chamber and seal it with type II restorative glassionomer cement.

- Throughout the procedure, hydrate the animal's eye and monitor its breathing and heartbeat, in order to provide immediate care should any emergency or complication arise.

- Monitor animals until after anaesthesia has worn off. The postoperative recovery will depend upon basic sanitary care, place (cage) in which animals are being kept, proper ventilation and hygiene.

- Consider rodents to be living beings whose biological responses are similar to humans', but faster, hence, whenever this model is used, results and their extrapolation to humans should be interpreted carefully.

To conclude, the experimental protocol presented herein enables the study of biological responses that would otherwise be ethically inaccessible in humans and could not be replicated effectively by using extracted teeth. We consider that this model for experimental root canal treatment could contribute to future research, unravelling a variety of aspects related to endodontic treatment. 


\section{ACKNOWLEDGEMENTS}

The authors are grateful to Carlos Bárcenas for his expert assistance in animal care and in handling animals during procedures, Laboratory Technicians Mariela Lacave and Paula Rocha for processing the samples and obtaining the histological sections, and Prof. Dr. Patricia M. Mandalunis for kindly reviewing the manuscript.

\section{FUNDING}

This work was supported by a grant from University of Buenos Aires, UBACYT Program \# 20020160100034BA

\section{REFERENCES}

1. Jara CM, Hartmann RC, Böttcher DE, Souza TS, et al. Influence of apical enlargement on the repair of apical periodontitis in rats. Int Endod J 2018;51:1261-1270. doi:10.1111/iej.12949

2. Yoneda N, Noiri Y, Matsui S, Kuremoto $\mathrm{K}$ et al. Development of a root canal treatment model in the rat. Sci Rep 2017;7:3315. doi:10.1038/s41598-017-03628-6

3. Dammaschke T. Rat molar teeth as a study model for direct pulp capping research in dentistry. Lab Anim 2010;44:1-6. doi: 10.1258/la.2009.008120.

4. Erausquin J and Muruzábal M. A method for root canal treatment in the molar of the rat. Oral Surg Oral Med Oral Pathol 1967 24: 540-546

5. Torabinejad M, Moazzami SM, Moaddel H, Hawkins J, et al. Effect of MTA particle size on periapical healing. Int Endod J 2017;50 Suppl 2:e3-e8. doi:10.1111/iej.12738

6. Borsatto MC, Correa-Afonso AM, Lucisano MP, Bezerra da Silva RA, et al. One-session root canal treatment with antimicrobial photodynamic therapy (aPDT): an in vivo study. Int Endod J 2016;49:511-518. doi:10.1111/ iej. 12486

7. Cruz A, Vera J, Gascón G, Palafox-Sánchez CA et al. Debris remaining in the apical third of root canals after chemomechanical preparation by using sodium hypochlorite and glyde: an in vivo study. J Endod 2014;40:1419-1423. doi:10.1016/j.joen.2014.05.013

8. Reames RL, Nickel JS, Patterson SS, Boone M et al. Clinical, radiographic, and histological study of endodontically treated retained roots to preserve alveolar bone. J Endod 1975;1:367-373. doi:10.1016/S0099-2399(75)80212-3

9. Stashenko P, Wang CY, Tani-ishii N, Yu SM. Pathogenesis of induced rat periapicallesions. Oral Surg Oral Med Oral Pathol 1994;78:494-502

10. Schour I, Massler M. The Teeth. In: Farris EJ, Griffith JQ, eds. The rat in the laboratory investigation. Philadelphia: Lippincott Company, 1942;104-165.

11. Canzobre MC, Paganelli AR, Ríos H. Effect of periapical inflammation on calcium binding proteins and ERK in the trigeminal nucleus. Acta Odontol Latinoam 2019;32:103110.

12. Santos JM, Pereira S, Sequeira DB, Messias AL, et al. Biocompatibility of a bioceramic silicone-based sealer in subcutaneous tissue. J Oral Sci 2019;61:171-177. doi:10.2334/josnusd.18-0145.

13. Kaplan AE, Ormaechea MF, Picca M, Canzobre MC et al. Rheological properties and biocompatibility of endodontic

\section{CORRESPONDENCE:}

Sharon R. Oyhanart

Cátedra de Histologia y Embriología

Facultad de Odontología

Marcelo T. de Alvear 2142

Buenos Aires, Argentina

sharon.oyhanart@odontologia.uba.ar sealers. Int Endod J 2003;36:527-532. doi:10.1046/j.13652591.2003.00683.x

14. Gutmann JL, Fan B. Tooth morphology, isolation and access. In. Hargreaves KM, Cohen S \& Berman LH, eds. Cohen's pathways of the pulp. St. Louis: Mosby Elsevier, 2016.130-208

15. Wolfensohn S, Lloyd M. Pain, stress and humane end points. In: Wolfensohn S, Lloyd M, eds. Handbook of Laboratory Animal Management and Welfare. NJ: Wiley-Blackwell, 2003. 59-73

16. Bozal CB, Sánchez LM, Mandalunis PM, Ubios ÁM. Histomorphometric study and three-dimensional reconstruction of the osteocyte lacuno-canalicular network one hour after applying tensile and compressive forces. Cells Tissues Organs 2013;197:474-483. doi:10.1159/000347237

17. Mandalunis PM, Steimetz T, Castiglione JL, Ubios AM. Alveolar bone response in an experimental model of renal failure and periodontal disease: a histomorphometric and histochemical study. J Periodontol 2003;74:1803-1807. doi:10.1902/jop.2003.74.12.1803

18. Nagendrababu V, Kishen A, Murray PE, Nekoofar MH, et al. Preferred reporting items for animal studies in Endodontology: a development protocol. Int Endod J 2019;52:1290-1296. doi:10.1111/iej.13125

19. Masson E, Hennet PR, Calas PL. Apical root canal anatomy in the dog. Endod Dent Traumatol 1992;8: 109-112. doi:10.1111/j.1600-9657.1992.tb00446.x

20. Hernández SZ, Negro VB, Maresca BM. Morphologic features of the root canal system of the maxillary fourth premolar and the mandibular first molar in dogs. J Vet Dent 2001;18:9-13. doi:10.1177/089875640101800101

21. Matsumoto N, Minakami M, Hatakeyama J, Haruna C, et al. Histologic evaluation of the effects of Emdogain gel on injured root apex in rats. J Endod. 2014;40:1989-1994. doi:10.1016/j.joen.2014.08.024

22. Wagner C, Barth VC Jr, de Oliveira SD, Campos MM. Effectiveness of the proton pump inhibitor omeprazole associated with calcium hydroxide as intracanal medication: an in vivo study. J Endod 2011;37:1253-1257. doi:10.1016/j. joen.2011.06.011

23. Arias Martinez ZR, Naruishi K, Yamashiro K, Myokai $\mathrm{F}$ et al. Gene profiles during root canal treatment in experimental rat periapical lesions. J Endod 2007;33:936943. doi:10.1016/j.joen.2007.04.016

24. Gómez PA, Cabrini RL. Anatomic variations of the root canal of the rat according to age. Acta Odontol Latinoam $2004 ; 17: 39-42$ 
25. Jou YT, Karabucak B, Levin J, Liu D. Endodontic working width: current concepts and techniques. Dent Clin North Am 2004;48:323-335. doi:10.1016/j.cden.2003.12.006

26. Zhao D, Shen Y, Peng B, Haapasalo M. Root canal preparation of mandibular molars with 3 nickel-titanium rotary instruments: a micro-computed tomographic study. J Endod 2014;40:1860-1864. doi:10.1016/j.joen.2014.06.023

27. Wu MK, Wesselink PR. A primary observation on the preparation and obturation of oval canals. Int Endod $\mathrm{J}$ 2001;34:137-141. doi:10.1046/j.1365-2591.2001.00361.x

28. Siqueira Junior JF, Rôças IDN, MarcelianoAlves MF, Pérez AR, et al. Unprepared root canal surface areas: causes, clinical implications, and therapeutic strategies. Braz Oral Res 2018;18-32: e65. doi: 10.1590/18073107bor-2018.vol32.0065.

29. Alattar S, Nehme W, Diemer F, Naaman A. The influence of brushing motion on the cutting behavior of 3 reciprocating files in oval-shaped canals. J Endod 2015;41:703-9. doi: 10.1016/j.joen.2014.12.016.

30. Marchi GM, Mitsui FHO, Cavalcanti AN. Effect of remaining dentine structure and thermal-mechanical aging on the fracture resistance of bovine roots with different post and core systems. Int Endod J 2008; 41:969-76. doi: $10.1111 / \mathrm{j} .1365-2591.2008 .01459 . \mathrm{x}$

31. Djomehri SI, Candell S, Case T, Browning A et al. Mineral density volume gradients in normal and diseased human tissues. PLoS One 2015;10(4): e0121611 doi:10.1371/ journal.pone.0121611

32. Foster BL. Methods for studying tooth root cementum by light microscopy. Int J Oral Sci 2012; 4:119-128. doi:10.1038/ijos.2012.57

33. Abou-Rass M, Frank AL, Glick DH. The anticurvature filing method to prepare the curved root canal. J Am Dent Assoc 1980;101:792-794. doi:10.14219/jada.archive.1980.0427

34. Ahn S-Y, Kim H-C, Kim E. Kinematic effects of nickeltitanium instruments with reciprocating or continuous rotation motion: a systematic review of in vitro studies. J Endod 2016;42, 1009-1017. doi:10.1016/j.joen.2016.04.002

35. Ng Y-L, Mann V, Rahbaran S, Lewsey J et al. Outcome of primary root canal treatment: systematic review of the literature -- part 2. Influence of clinical factors. Int Endod J 2008;41:6-31. doi:10.1111/j.1365-2591.2007.01323.x

36. Xie Q, Li X, Xu X.The difficult relationship between occlusal interferences and temporomandibular disorder - insights from animal and human experimental studies. J Oral Rehabil 2013;40:279-295. doi:10.1111/ joor. 12034

37. Sidhu SK.Glass-ionomer cement restorative materials: a sticky subject? Aust Dent J 2011;56 Suppl 1:23-30. doi:10.1111/j.1834-7819.2010.01293.x 